\title{
Nurse and Patient Perceptions and Preferences for Subcutaneous Autoinjectors for Inflammatory Joint or Bowel Disease: Findings from a European Survey
}

Steve Fenwick $\cdot$ Kunal Thakur $\cdot$ Duncan Munro

Received: December 21, 2018 / Published online: February 21, 2019

(C) The Author(s) 2019

\section{ABSTRACT}

Introduction: Imraldi $^{\mathrm{TM}}$ is a biosimilar of the anti-tumor necrosis factor (TNF) monoclonal antibody adalimumab and was recently approved in Europe for the treatment of various inflammatory conditions. Imraldi is administered via an autoinjector device that features distinct design attributes compared with other biologic TNF inhibitor autoinjectors, such as the Humira (adalimumab) Pen ${ }^{\circledR}$ and Enbrel ${ }^{\circledR}$ (etanercept) MyClic ${ }^{\circledR}$ Pen were developed by the relevant pharmaceutical companies. The aim of this study was to evaluate patients' and nurses' preferences for the Imraldi versus Humira or Enbrel MyClic autoinjectors in the UK and Germany. Methods: Patients with inflammatory joint or bowel disease and nurses with experience in

Enhanced digital features To view enhanced digital features for this article go to https://doi.org/10.6084/ m9.figshare.7649120.

Electronic supplementary material The online version of this article (https://doi.org/10.1007/s40744019-0144-8) contains supplementary material, which is available to authorized users.

S. Fenwick $(\bowtie)$

Biogen Idec, Maidenhead, UK

e-mail: steve.fenwick@biogen.com

K. Thakur

Biogen International GmbH, Baar, Switzerland

D. Munro

Cello Health Insight, London, UK educating patients with these conditions on self-injection participated in two survey studies, the first comparing the Imraldi and Humira autoinjectors and the second comparing the Imraldi and Enbrel MyClic autoinjectors.

Results: Overall, 101 nurses (UK, $n=50$; Germany, $n=51$ ) and 151 patients (UK, $n=90$; Germany, $n=61$ ) participated in both studies. In the first study, $85 \%$ of nurses and $78 \%$ of patients preferred the Imraldi autoinjector over the Humira autoinjector $(P<0.001)$; in the second study, $86 \%$ of nurses and $79 \%$ of patients preferred the Imraldi autoinjector over the Enbrel MyClic autoinjector $(P<0.001)$. Top reasons for preferring the Imraldi autoinjector included ease of use, ease of grip, and its button-free initiation mechanism. Most nurses indicated they would recommend the Imraldi autoinjector over the Humira and Enbrel MyClic autoinjectors, and most patients indicated they would choose the Imraldi autoinjector over the Humira and Enbrel MyClic autoinjectors to continue treatment.

Conclusion: Nurses and patients in the UK and Germany preferred the Imraldi autoinjector over both the Humira and Enbrel MyClic autoinjectors, which may be a consideration, along with other factors, for treatment decisions in the management of patients with inflammatory joint or bowel disease.

Funding: Biogen International $\mathrm{GmbH}$.

Keywords: Adalimumab; Autoinjector; Biosimilar; Humira; Imraldi ${ }^{\mathrm{TM}}$; Inflammatory 
bowel disease; MyClic $®$; Rheumatoid arthritis; Tumor necrosis factor

\section{INTRODUCTION}

Biologic tumor necrosis factor (TNF) inhibitor therapies are routinely used in the USA and Europe to treat patients with inflammatory disorders, such as rheumatoid arthritis and inflammatory bowel disease, and these have greatly improved outcomes in these patients [1-4]. Humira ${ }^{\circledR}$ (adalimumab) (AbbVie Inc., North Chicago, IL, USA) and Enbrel ${ }^{\circledR}$ (etanercept) (Immunex Corp., Thousand Oaks, CA, USA) are commonly prescribed biologic TNF inhibitors for the treatment of inflammatory joint disorders, such as rheumatoid arthritis, axial spondyloarthritis, and psoriatic arthritis [5-8]. Humira, but not Enbrel, is also indicated for the treatment of Crohn's disease and ulcerative colitis [5-8]. To increase patient access to these highly effective yet costly biologic therapies, anti-TNF biosimilars have been developed in recent years as more affordable alternatives [9]. However, medication nonadherence is common in patients receiving biologic anti-TNF treatment and is associated with increased disease activity and flares, loss of responsiveness to anti-TNF treatment, poorer quality of life, increased healthcare expenditures, and higher disability in patients with chronic inflammatory joint or bowel disease [10-13]. Improving adherence could substantially improve treatment efficacy and mitigate costs.

Biologic TNF inhibitor autoinjectors, such as the Humira (adalimumab) Pen ${ }^{\circledR}$ and Enbrel ${ }^{\circledR}$ (etanercept) MyClic ${ }^{\circledR}$ Pen, were developed to improve medication delivery and adherence and sustain long-term efficacy [8]. A number of studies have indicated that both patients with inflammatory conditions and nurses tend to prefer autoinjectors over prefilled syringes, as they consider autoinjectors easier to use, more convenient, and less painful [14-16]. Further improvements in autoinjector design attributes, such as ease of grip and ease of dose administration, could further optimize patient comfort and adherence, particularly for patients with inflammatory joint disease who can often find self-injection challenging due to compromised manual dexterity [17-22].

Imraldi $^{\mathrm{TM}}$ (SB5, adalimumab) (Biogen Inc., Cambridge, MA, USA), a biosimilar of the antiTNF monoclonal antibody Humira (adalimumab), was approved by the European medicines Agency in 2017 for the treatment of various inflammatory conditions, including rheumatoid arthritis, axial spondyloarthritis, psoriatic arthritis, Crohn's disease, and ulcerative colitis $[23,24]$. The Imraldi autoinjector, a latex-free, single-dose prefilled pen, was designed to ease and simplify the process of selfinjection. To improve grip, it features a nonslip surface and a rounded four-sided shape. To facilitate self-injection, it clicks audibly to indicate the start and end of dose administration, features a button-free initiation mechanism and a small needle size, and has a large medication viewing window with an indicator to confirm injection is complete. Head-to-head comparative studies of the Imraldi autoinjector versus other biologic TNF inhibitor autoinjectors are needed to determine whether the Imraldi autoinjector's attributes improve patient and nurse satisfaction. To address this gap, simulated-use studies were conducted with the Imraldi, Humira, and Enbrel MyClic autoinjectors to evaluate the autoinjector preferences of both patients with inflammatory joint or bowel disease and nurses who have experience in educating patients with these conditions on self-injection.

\section{METHODS}

Two survey studies, each with nurses and patients, were conducted in the UK and Germany. The first study compared the Imraldi and Humira autoinjectors, and the second study compared the Imraldi and Enbrel MyClic autoinjectors. Both studies were executed by Cello Health Insight, an independent healthcare market research agency. Cello Health Insight is a member of the British Healthcare Business Intelligence Association and the European Pharmaceutical Market Research Association, and this research was conducted in accordance with their guidelines on market 
research, including relevant European privacy legislation. All procedures performed in studies involving human participants were in accordance with the ethical standards of the national research committee and with the 1964 Helsinki declaration and its later amendments or comparable ethical standards. Nurses and patients provided written informed consent before participating in the study.

\section{Participant Recruitment, Screening, and Eligibility}

Nurses and patients were recruited to participate in both studies by local recruitment agencies based in the UK and Germany. Recruitment was via panel databases (lists of people who have previously opted in to be contacted for market research purposes; membership was reliant on relevant privacy permission), which was supplemented by recruitment through patient associations and support groups.

Only nurses with sufficient experience with autoinjector devices were eligible to participate in the studies. Specifically, nurses were screened to ensure they were a practice nurse/nurse practitioner, rheumatology specialist nurse, or gastroenterology specialist nurse in the UK or Germany with $\geq 1$ year of experience and $>75 \%$ of their time dedicated to direct patient care. In addition, nurses needed to have experience in patient education and training with regard to using biologic therapy that involves self-injection, familiarity with how the Humira autoinjector is used, and experience managing $\geq 10$ patients with inflammatory joint disease, Crohn's disease, or ulcerative colitis who self-administer a biologic each month, including $\geq 3$ patients who use the Humira autoinjector (although nurses did not have to personally train those patients).

Patients were screened to ensure they were aged 18-65 years and had a diagnosis of rheumatoid arthritis, psoriatic arthritis, axial spondyloarthritis, ulcerative colitis, or Crohn's disease. Patients were required to have been injecting Humira themselves via an autoinjector device for $\geq 3$ months at the time of screening. However, prior experience with the
Imraldi or MyClic autoinjectors was not required for study enrollment.

\section{Study Questionnaire and Procedures}

Two surveys were run as face-to-face interviews using training devices with neither needles nor active ingredients. Before initiating the study, participants were informed that they were participating in a market research study sponsored by a pharmaceutical company and designed to understand perceptions of medical devices and reactions to a potential new autoinjector. A moderator was present throughout each interview. The 20-min computer-based questionnaire evaluating the Imraldi versus Humira autoinjectors was completed first, followed by a 10 - to 15 -min break. The same nurse and patient participants then completed the 20-min computer-based questionnaire evaluating the Imraldi versus Enbrel MyClic autoinjectors.

The nurse and patient questionnaires, which include show cards with illustrations of each autoinjector, are available in the Electronic Supplementary Material (ESM) Appendix (additional illustrations and information on each autoinjector can be found in their respective European public assessment report [EPAR] product information documents [7, 8, 25]). The questionnaires were divided into four sections. In the first section, all participants were asked about their prior experience with and awareness of various autoinjector devices; in addition, nurses were asked to rate the importance of autoinjector design in treatment selection and medication adherence for patients with inflammatory joint or bowel diseases. In the second section, the moderator provided participants with show cards illustrating how to use each autoinjector before allowing them to handle training versions of each one. The order in which the two autoinjectors were introduced was randomized for each participant interview. In the third section of each questionnaire, participants indicated which of the two autoinjectors they preferred and wrote their reasons for that preference. Participants were then asked for their preference of autoinjector based on specific attributes, including: (1) ease of use, (2) ease 
of assessing solution clarity, (3) indication that a full dose was administered, (4) audio signals, (5) ease of grip, and (6) perceived ease of administering a dose. In addition, nurses were asked which autoinjector they would recommend to others and which would be easier to teach patients how to use, and patients were asked which autoinjector they would prefer to use to continue treatment. The majority of questions in this section of the questionnaire had previously been validated in a study of patients with rheumatoid arthritis, nurses, and rheumatologists [20]. The final section of the questionnaire included questions on participant demographics, including gender and age.

\section{Statistical Analyses}

For each questionnaire item, a binomial test was employed to identify statistical significance $(P<0.05)$. Separate tests were run for the Imraldi versus Humira autoinjectors and the Imraldi versus Enbrel MyClic autoinjectors, and no comparisons were made between the Humira and Enbrel MyClic autoinjectors or among all three autoinjectors. Overall preference was identified as the primary indicator prior to commencing the market research, and this question was asked ahead of the other comparison metrics.

\section{RESULTS}

\section{Participant Characteristics}

A total of 101 nurses (50 from the UK and 51 from Germany) participated in both studies (Table 1). Rheumatology specialist nurses and gastroenterology specialist nurses each constituted half of all nurse participants. All nurses had prior familiarity with the Humira autoinjector (100\%) and/or the Enbrel MyClic autoinjector (65\%), and the majority of nurses trained/supported patients self-administering using the Humira autoinjector (96\%) or the Enbrel MyClic autoinjector (52\%). On a 7-point scale $(1=$ not at all important; $4=$ neither important nor unimportant; $7=$ extremely important), nurses rated a mean score of 6.27 for the importance of the autoinjector design when selecting a treatment for inflammatory joint or bowel disease. Similarly, nurses rated a mean score of 6.54 on a 7 -point scale $(1=$ no impact at all; 7 = great positive impact) for the importance of patients being comfortable with using a device in increasing adherence during the treatment of inflammatory joint or bowel disease.

Additionally, a total of 151 patients (90 from the UK and 61 from Germany) participated in both studies (Table 2). Patients had a variety of inflammatory conditions, including rheumatoid arthritis (37\%), ulcerative colitis (23\%), Crohn's disease (30\%), psoriatic arthritis (15\%), and axial spondyloarthritis (3\%). Of the enrolled patients, $54 \%$ were female, $61 \%$ were aged $>40$ years, and 95 and $18 \%$ were previously aware of the Humira and Enbrel MyClic autoinjectors, respectively, with $92 \%$ using the Humira autoinjector and 3\% using the Enbrel MyClic autoinjector at the time of the study.

\section{Questionnaire Results: Imraldi Versus Humira Autoinjectors}

In the first study, $85 \%$ of nurses and $78 \%$ of patients preferred the Imraldi autoinjector over the Humira autoinjector (Fig. 1). When the data were analyzed according to geographic region, the Imraldi autoinjector was preferred by $90 \%$ of nurses and $84 \%$ of patients in the UK and $80 \%$ of nurses and $69 \%$ of patients in Germany (ESM Tables S1 and S2). The main reasons for preferring the Imraldi autoinjector over the Humira autoinjector were: convenient and easy to use/inject/handle $(60 \%$ of nurses and $63 \%$ of patients), fits well and does not slip in hand (43 and 40\%, respectively), has an initiation mechanism that requires no thumb trigger button (41 and 30\%, respectively), has a large and visual control that is suitable for hearingimpaired patients (42 and 27\%, respectively), has a double click that is suitable for visually impaired patients (49 and 38\%, respectively), and requires removal of only one cap (34 and 33\%, respectively; ESM Tables S3 and S4). Most nurses and patients indicated that the Imraldi 
Table 1 Nurse characteristics

\begin{tabular}{lccc}
\hline Nurse characteristics & UK $(\boldsymbol{n}=\mathbf{5 0})$ & Germany $(\boldsymbol{n}=\mathbf{5 1})$ & All nurses $(\boldsymbol{n}=\mathbf{1 0 1})$ \\
\hline Specialty, $n(\%)$ & & & \\
Rheumatology & $25(50)$ & $26(51)$ & $51(50)$ \\
Gastroenterology & $25(50)$ & $25(49)$ & $50(50)$ \\
Mean (SD) percentage of time spent on direct patient care & $88.94(6.91)$ & $89.71(7.38)$ & $89.33(7.12)$ \\
Device familiarity, $n$ (\%) & & & \\
Humira & & & $101(100)$ \\
Aware of & $50(100)$ & $51(100)$ & $97(96)$ \\
Support patients with device & $48(96)$ & $49(96)$ & $66(65)$ \\
Enbrel & & & $53(52)$ \\
Aware of & $28(56)$ & $38(75)$ & \\
Support patients with device & $25(50)$ & $28(55)$ & $56(55)$ \\
Others & & & $47(47)$ \\
Aware of & $23(46)$ & $33(65)$ & \\
Support patients with device & $23(46)$ & $24(47)$ & \\
\hline
\end{tabular}

$S D$ Standard deviation

autoinjector outperformed the Humira autoinjector with regard to ease of use, ease of grip, ease of dose administration, and feedback after administering a full dose (Fig. 2). These results remained consistent when participants from the UK and Germany were analyzed separately (ESM Tables S1 and S2). Consequently, 83\% of all nurses (UK 94\%; Germany 73\%) thought it would be easier to teach patients how to use the Imraldi autoinjector than how to use the Humira autoinjector, and $87 \%$ of all nurses (UK $92 \%$; Germany 82\%) would recommend the Imraldi autoinjector over the Humira autoinjector (Fig. 1a; ESM Table S1). Furthermore, 79\% of all patients (UK 86\%; Germany 70\%) would select the Imraldi autoinjector over the Humira autoinjector to continue treatment (Fig. 1b; ESM Table S2). Patient study results remained consistent regardless of age or diagnosed inflammatory condition, and nurse study results remained consistent regardless of specialty (ESM Tables S1 and S2).

\section{Questionnaire Results: Imraldi Versus Enbrel MyClic Autoinjectors}

In the second study, $86 \%$ of nurses and $79 \%$ of patients preferred the Imraldi autoinjector over the Enbrel MyClic autoinjector (Fig. 3). When the data were analyzed according to geographic region, the Imraldi autoinjector was preferred by $88 \%$ of nurses and $84 \%$ of patients in the UK and $84 \%$ of nurses and $70 \%$ of patients in Germany (ESM Tables S5 and S6). The top reasons indicated for the preference of the Imraldi autoinjector over the Enbrel MyClic autoinjector were: convenient and easy to use/inject/ handle ( $45 \%$ of nurses and $65 \%$ of patients), fits well and does not slip in hand (57 and 51\%, respectively), and has an automatic start that requires no thumb trigger button (45 and 27\%, respectively; ESM Tables S7 and S8). Nurses and patients strongly preferred the Imraldi autoinjector over the Enbrel MyClic autoinjector for its ease of use, ease of grip, and ease of dose administration (Fig. 4). These results remained 
Table 2 Patient characteristics

\begin{tabular}{|c|c|c|c|}
\hline Patient characteristics & $\mathrm{UK}(n=90)$ & Germany $(n=61)$ & All patients $(n=151)$ \\
\hline \multicolumn{4}{|l|}{ Gender, $n(\%)$} \\
\hline Male & $42(47)$ & $28(46)$ & $70(46)$ \\
\hline Female & $48(53)$ & $33(54)$ & $81(54)$ \\
\hline \multicolumn{4}{|l|}{ Age, $n(\%)$} \\
\hline $18-25$ years & $7(8)$ & $3(5)$ & $10(7)$ \\
\hline $26-30$ years & $12(13)$ & $3(5)$ & $15(10)$ \\
\hline $31-35$ years & $8(9)$ & $7(11)$ & $15(10)$ \\
\hline $36-40$ years & $14(16)$ & $5(8)$ & $19(13)$ \\
\hline $41-50$ years & $22(24)$ & $15(25)$ & $37(25)$ \\
\hline $51-65$ years & $27(30)$ & $28(46)$ & $55(36)$ \\
\hline \multicolumn{4}{|l|}{ Condition, $n(\%)$} \\
\hline Rheumatoid arthritis & $35(39)$ & $21(34)$ & $56(37)$ \\
\hline Ulcerative colitis & $17(19)$ & $17(28)$ & $34(23)$ \\
\hline Crohn's disease & $30(33)$ & $16(26)$ & $46(30)$ \\
\hline Psoriatic arthritis & $13(14)$ & $10(16)$ & $23(15)$ \\
\hline Axial spondyloarthritis & $3(3)$ & $1(2)$ & $4(3)$ \\
\hline \multicolumn{4}{|l|}{ Device familiarity, $n(\%)$} \\
\hline \multicolumn{4}{|l|}{ Humira } \\
\hline Currently used & $78(87)$ & $61(100)$ & $139(92)$ \\
\hline Have used in the past & $68(76)$ & $3(5)$ & $71(47)$ \\
\hline Aware of & $83(92)$ & $61(100)$ & $144(95)$ \\
\hline \multicolumn{4}{|l|}{ Enbrel } \\
\hline Currently used & $5(6)$ & $0(0)$ & $5(3)$ \\
\hline Have used in the past & $10(11)$ & $7(11)$ & $17(11)$ \\
\hline Aware of & $10(11)$ & $17(28)$ & $27(18)$ \\
\hline \multicolumn{4}{|l|}{ Others } \\
\hline Currently used & $11(12)$ & $3(5)$ & $14(9)$ \\
\hline Have used in the past & $9(10)$ & $3(5)$ & $12(8)$ \\
\hline Aware of & $17(19)$ & $7(11)$ & $24(16)$ \\
\hline
\end{tabular}

consistent for both the UK and German cohorts when evaluated separately by geographic region (ESM Tables S5 and S6). Nurses and patients also preferred the Imraldi autoinjector over the Enbrel MyClic autoinjector when evaluating ease of assessing clarity of the injection 
a

Imraldi Humira $\square$ Both are the same

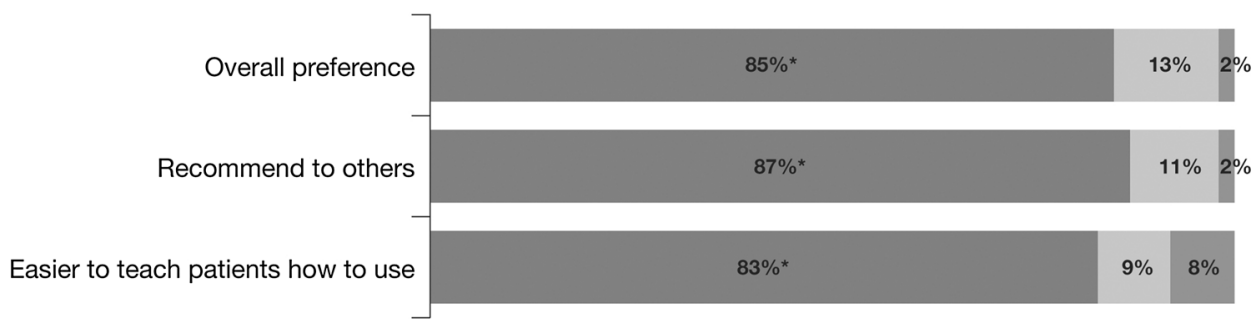

b

Imraldi Humira $\quad$ Both are the same

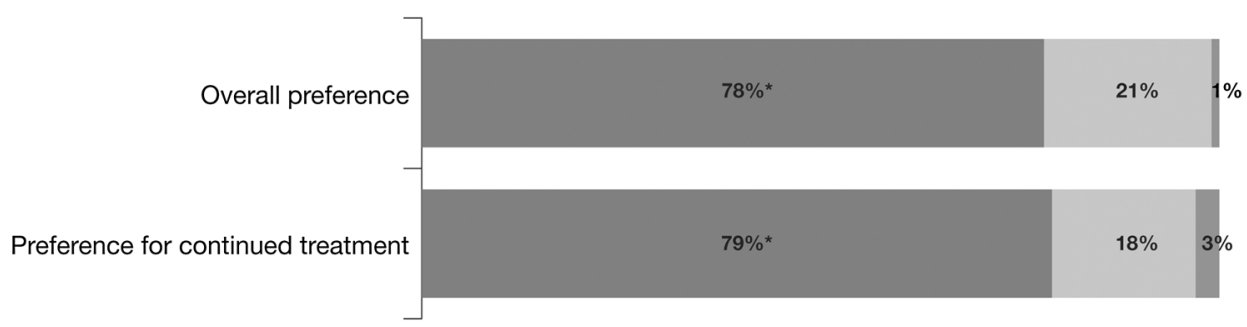

Fig. 1 Nurse (a) and patient (b) overall preferences for Imraldi versus Humira autoinjectors. Asterisk indicates that the Imraldi autoinjector was selected significantly more often than the Humira autoinjector $(P<0.001)$

solution, feedback after administering a full dose, and audio signals; compared with other questions, a higher percentage of participants chose 'no preference' for these questions, although the percentage of participants who preferred the Enbrel MyClic autoinjector remained low $(5-15 \%)$. Overall, $82 \%$ of all nurses (UK 86\%; Germany 78\%) thought it would be easier to teach patients how to use the Imraldi autoinjector than how to use the Enbrel MyClic autoinjector, and $85 \%$ of all nurses (UK 86\%; Germany 84\%) would recommend the Imraldi autoinjector over the Enbrel MyClic autoinjector (Fig. 3a; ESM Table S5). Moreover, $81 \%$ of all patients (UK $88 \%$; Germany $72 \%$ ) indicated that they would select the Imraldi autoinjector over the Enbrel MyClic autoinjector to continue treatment (Fig. 3b; ESM Table S6). Patient study results remained consistent across age groups and diagnosed inflammatory conditions. Nurse study results stayed consistent irrespective of specialization or prior familiarity with the Enbrel MyClic autoinjector (ESM Tables S5 and S6).

\section{DISCUSSION}

In the studies reported here, questionnaires were administered to patients with inflammatory joint or bowel disease $(n=151)$ and to nurses with experience in working with these conditions $(n=101)$, in both the UK and Germany, to ascertain their preference of autoinjector (the Imraldi autoinjector vs. the Humira and Enbrel MyClic autoinjectors) for subcutaneous delivery of a biologic TNF inhibitor. When evaluating the overall autoinjector, as well as individual characteristics of the autoinjector, a higher proportion of both nurses and patients preferred the Imraldi autoinjector over the Humira and Enbrel MyClic autoinjectors. Nurses indicated that they would recommend the Imraldi autoinjector over both the Humira and Enbrel MyClic autoinjectors, and they believed that use of the Imraldi autoinjector would be easier to teach to patients. Furthermore, the majority of patients indicated that they would prefer to continue treatment with the Imraldi autoinjector over the Humira or Enbrel MyClic autoinjectors. Importantly, for patients, results were consistent irrespective of 


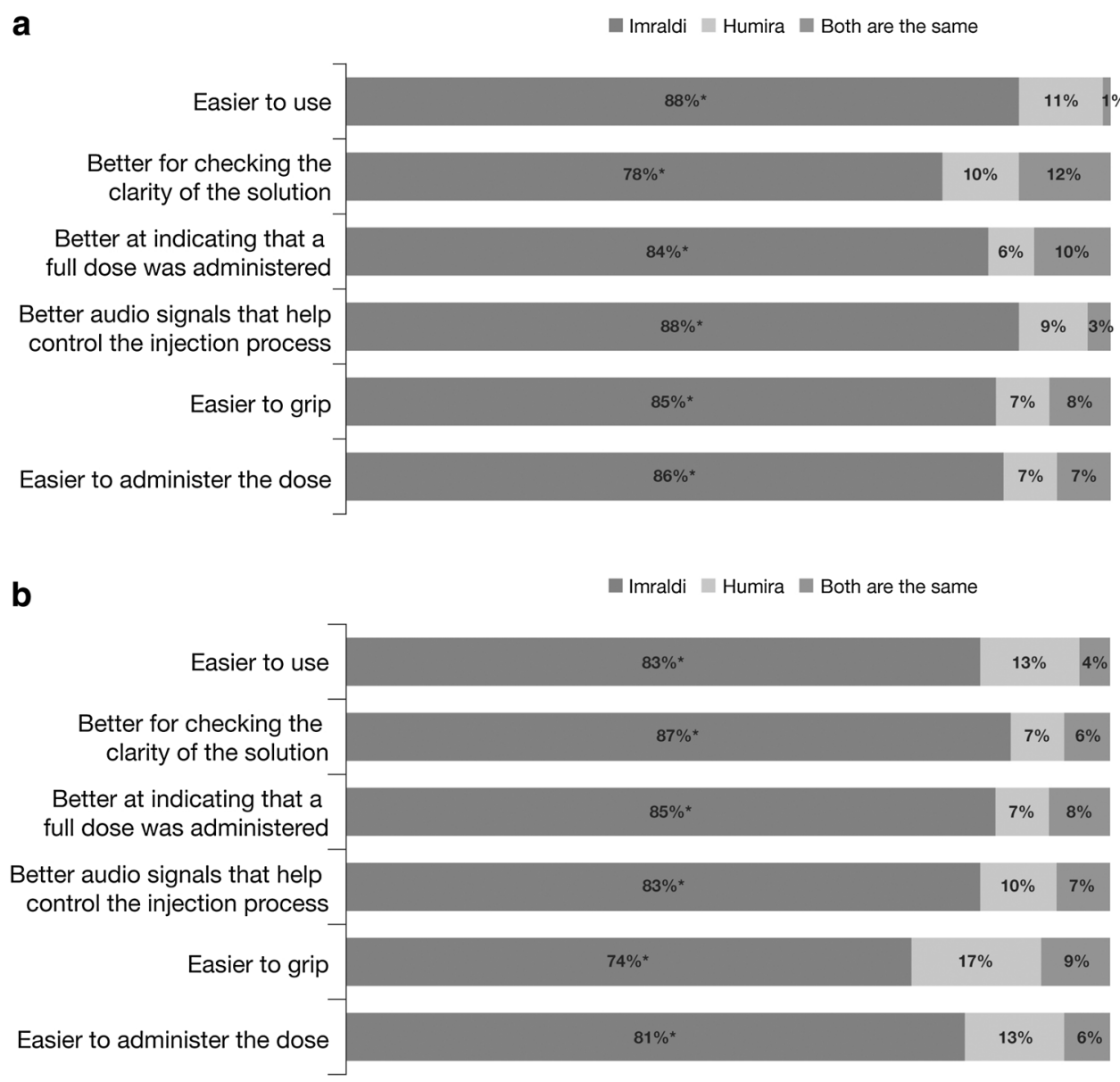

Fig. 2 Nurse (a) and patient (b) preferences for Imraldi versus Humira autoinjectors based on attributes. Asterisk indicates that the Imraldi autoinjector was selected significantly more often than the Humira autoinjector $(P<0.001)$

age, country, or condition; for nurses, results were consistent regardless of country, specialty, or prior familiarity with the Enbrel MyClic autoinjector.

Prior studies had identified 'easy to operate the self-injection' and 'easy to grip the autoinjector' as the most important attributes for both patients and nurses using or training patients for use of an autoinjector device for self-injection [17-19]. Consistent with prior studies, in this current study these attributes were the most frequently reported reasons for both patients' and nurses' overall preference of the Imraldi autoinjector over the Humira and Enbrel MyClic autoinjectors. Patients and nurses also preferred the Imraldi autoinjector's button-free initiation mechanism over the activation button required for injection with the Humira and
Enbrel MyClic autoinjectors. Many participants indicated that the initiation mechanism was one of their main reasons for preferring the Imraldi autoinjector. The improved grip and usability of the Imraldi autoinjector were indicated as being of utmost importance for patients with inflammatory joint disease, who can struggle with self-injection due to joint pain and limited manual dexterity [21, 22]. Considering the prevalence of nonadherence in patients with chronic inflammatory conditions $[10,11]$, the improved design of the Imraldi autoinjector may help to sustain long-term effectiveness of this biologic TNF inhibitor by optimizing patient comfort with self-administration of treatment.

With multiple anti-TNF biosimilars available, device preference may be a contributory 


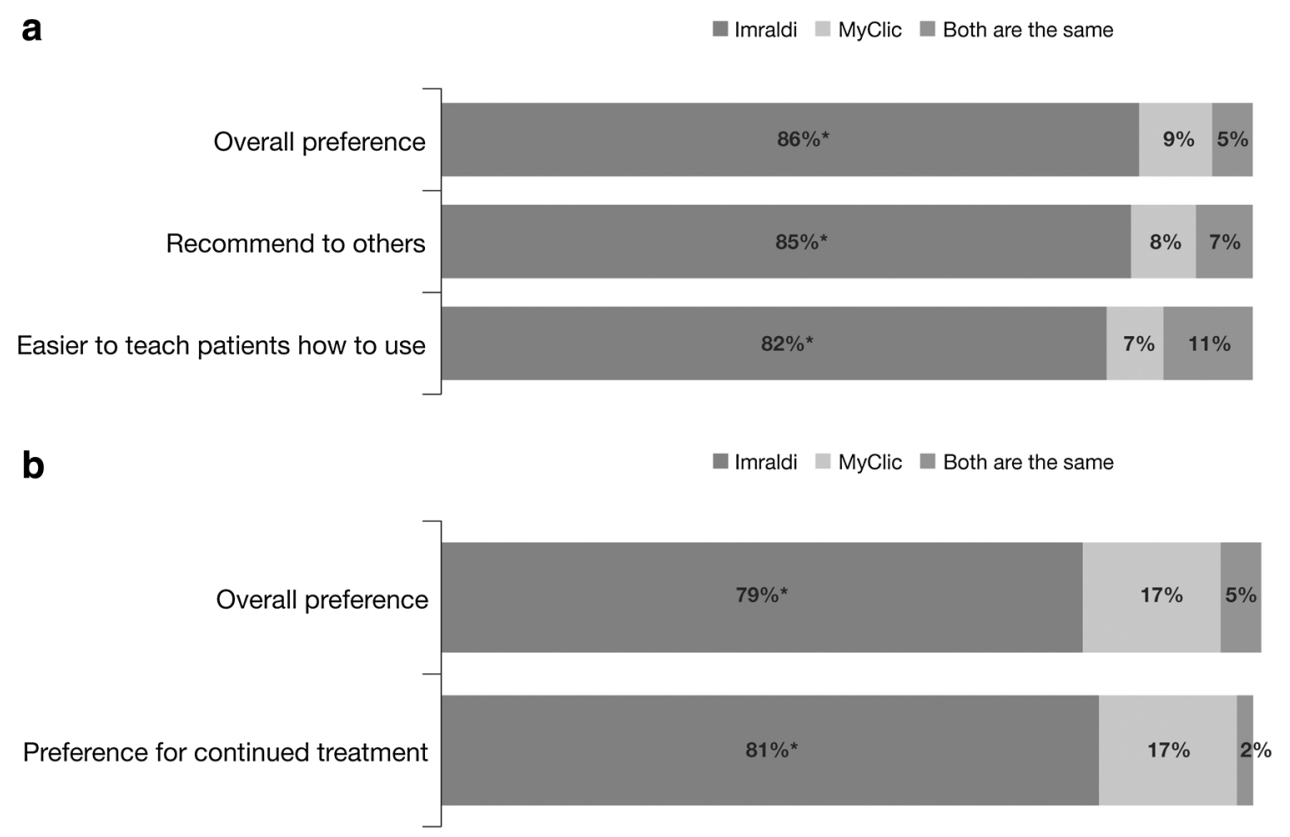

Fig. 3 Nurse (a) and patient (b) overall preference for Imraldi versus Enbrel MyClic autoinjectors. Asterisk indicates that the Imraldi autoinjector was selected significantly more often than the Enbrel MyClic autoinjector $(P<0.001)$

factor in physician selection of treatment for patients with inflammatory joint or bowel disease in whom a biologic therapy is indicated. Several recent studies have reported that patients and nurses prefer the newer Benepali ${ }^{\circledR}$ autoinjector (Biogen Inc., Cambridge, MA, USA) over the Enbrel MyClic autoinjector based on evaluation of the overall autoinjector and most autoinjector design characteristics [17, 18]. Collectively, the results of these past studies and the present study demonstrate that both patients and nurses tend to prefer design attributes incorporated into newly developed autoinjectors over those of older counterparts.

\section{Study Limitations}

Of note, the design of the study had some limitations. Participants' prior experience with the Humira and Enbrel MyClic autoinjectors may have negatively or positively biased their responses due to their familiarity with the devices (e.g., some participants may feel more comfortable with a known device, while others may be drawn to something new). Furthermore, the same nurses and patients participated in both studies; the questionnaire for evaluation of the Imraldi versus Humira autoinjectors always took place first, with the questionnaire for evaluation of the Imraldi versus Enbrel MyClic autoinjectors initiated after a 10- to 15-min break. At the time of the comparison against the Enbrel MyClic autoinjector, participants had prior training with Imraldi due to their participation in the first study and will have also realized that the Imraldi autoinjector was a focus of both studies. The study order may therefore have biased the Imraldi versus Enbrel MyClic autoinjector study results.

\section{CONCLUSIONS}

Results from these patient and nurse surveys suggest that rheumatology and gastroenterology nurses and patients with inflammatory joint or bowel disease prefer the Imraldi autoinjector over both the Humira and the Enbrel MyClic autoinjectors. The main reasons for this preference include the Imraldi autoinjector's initiation mechanism and its improved grip and ease of use. Consequently, nurses were more likely to recommend the Imraldi autoinjector than either of the other devices assessed, 


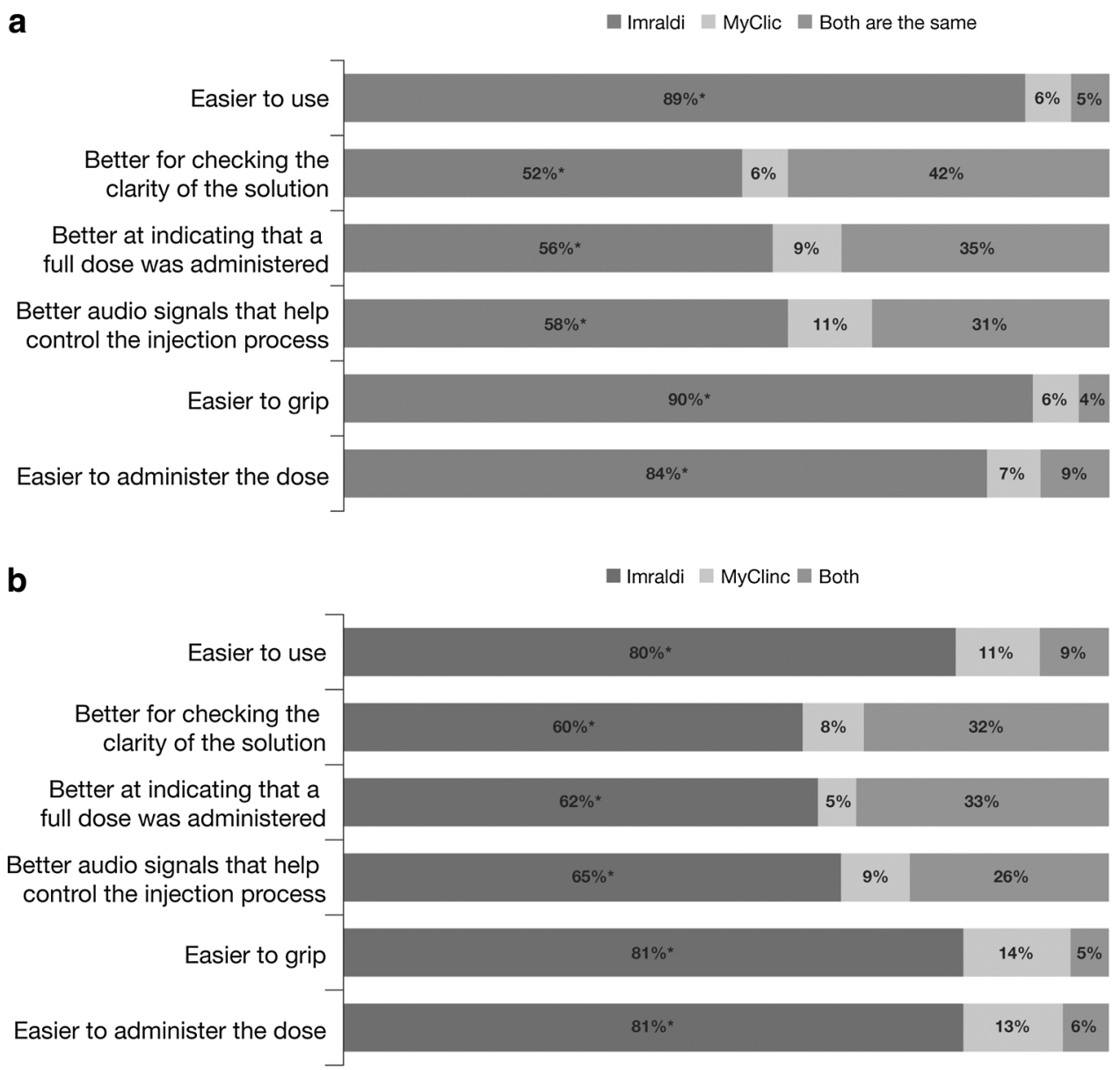

Fig. 4 Nurse (a) and patient (b) preferences for Imraldi versus Enbrel MyClic autoinjectors based on attributes. Asterisk indicates that the Imraldi autoinjector was selected significantly more often than the Enbrel MyClic autoinjector $(P<0.001)$

and patients selected the Imraldi autoinjector as their preferred device for continued treatment. The preferences for the Imraldi autoinjector expressed in these studies could possibly have implications, along with other treatment considerations, for future treatment decisions in the management of patients with inflammatory joint or bowel disease.

\section{ACKNOWLEDGEMENTS}

The authors would like to thank the nurses and patients who participated in this survey.
Funding. This study was sponsored by Biogen International $\mathrm{GmbH}$; funding for article processing charges was also provided by Biogen International $\mathrm{GmbH}$. All authors had full access to all of the data in this study and take complete responsibility for the integrity of the data and accuracy of the data analysis.

Medical Writing, Editorial, and Other Assistance. Editorial assistance in the preparation of this manuscript was provided by Diana Avery, PhD, of SciFluent Communications; support for this assistance was funded by Biogen. 
Authorship. All named authors meet the International Committee of Medical Journal Editors (ICMJE) criteria for authorship for this article, take responsibility for the integrity of the work as a whole, and have given their approval for this version to be published. Steve Fenwick and Kunal Thakur were involved in the conception and design of these studies, and all authors assisted in the development of the study methodology. Duncan Munro was responsible for the acquisition of data; statistical analysis and interpretation of the data; administrative, technical, and material support; and study supervision. All authors critically reviewed and revised the manuscript.

Disclosures. Steve Fenwick is an employee of and holds stock in Biogen. Kunal Thakur is an employee of and holds stock in Biogen. Duncan Munro is an employee of Cello Health Insight, which was commissioned by Biogen to conduct market research on their behalf.

Compliance with Ethics Guidelines. Cello Health Insight is a member of the British Healthcare Business Intelligence Association and the European Pharmaceutical Market Research Association, and this research was conducted in accordance with their guidelines on market research, including relevant European privacy legislation. All procedures performed in studies involving human participants were in accordance with the ethical standards of the national research committee and with the 1964 Helsinki declaration and its later amendments or comparable ethical standards. Informed consent was obtained from all individual participants included in the study.

Data Availability. The datasets during and/ or analyzed during the current study are available from the corresponding author on reasonable request.

Open Access. This article is distributed under the terms of the Creative Commons Attribution-NonCommercial 4.0 International License (http://creativecommons.org/licenses/ by-nc/4.0/), which permits any noncommercial use, distribution, and reproduction in any medium, provided you give appropriate credit to the original author(s) and the source, provide a link to the Creative Commons license, and indicate if changes were made.

\section{REFERENCES}

1. Smolen JS, Landewe R, Bijlsma J, et al. EULAR recommendations for the management of rheumatoid arthritis with synthetic and biological diseasemodifying antirheumatic drugs: 2016 update. Ann Rheum Dis. 2017;76:960-77.

2. Singh JA, Furst DE, Bharat A, et al. 2012 update of the 2008 American College of Rheumatology recommendations for the use of disease-modifying antirheumatic drugs and biologic agents in the treatment of rheumatoid arthritis. Arthritis Care Res (Hoboken). 2012;64:625-39.

3. Taylor PC, Feldmann M. Anti-TNF biologic agents: still the therapy of choice for rheumatoid arthritis. Nat Rev Rheumatol. 2009;5:578-82.

4. Neurath MF. Cytokines in inflammatory bowel disease. Nat Rev Immunol. 2014;14:329-42.

5. Immunex Corporation. ENBREL ${ }^{\circledR}$ (etanercept) injection [packet insert]. Thousand Oaks, CA: Immunex Corporation; 2018.

6. AbbVie Inc. HUMIRA ${ }^{\circledR}$ (adalimumab) injection [packet insert]. North Chicago, IL: AbbVie Inc.; 2019.

7. AbbVie Biotechnology GmbH. Humira solution for injection in pre-filled syringe [package insert]. Ludwigshafen, Germany: AbbVie Biotechnology GmbH Germany; 2008.

8. Pfizer Europe MA EEIG. Enbrel powder for solution for injection [package insert]. Brussels, Belgium: Pfizer Europe MA EEIG; 2010.

9. Azevedo V, Dörner T, Strohal R, et al. Biosimilars: considerations for clinical practice. Consid Med. 2017;1:13-8.

10. van den Bemt BJ, Zwikker HE, van den Ende $\mathrm{CH}$. Medication adherence in patients with rheumatoid arthritis: a critical appraisal of the existing literature. Expert Rev Clin Immunol. 2012;8:337-51.

11. Chan W, Chen A, Tiao D, Selinger C, Leong R. Medication adherence in inflammatory bowel disease. Intest Res. 2017;15:434-45. 
12. Borah BJ, Huang X, Zarotsky V, Globe D. Trends in RA patients' adherence to subcutaneous anti-TNF therapies and costs. Curr Med Res Opin. 2009;25:1365-77.

13. Fidder $\mathrm{HH}$, Singendonk $\mathrm{MM}$, van der Have $\mathrm{M}$, Oldenburg B, van Oijen MG. Low rates of adherence for tumor necrosis factor-alpha inhibitors in Crohn's disease and rheumatoid arthritis: results of a systematic review. World J Gastroenterol. 2013;19:4344-50.

14. Kivitz A, Cohen S, Dowd JE, et al. Clinical assessment of pain, tolerability, and preference of an autoinjection pen versus a prefilled syringe for patient self-administration of the fully human, monoclonal antibody adalimumab: the TOUCH trial. Clin Ther. 2006;28:1619-29.

15. Borras-Blasco J, Gracia-Perez A, Rosique-Robles JD, Castera MD, Abad FJ. Acceptability of switching adalimumab from a prefilled syringe to an autoinjection pen. Expert Opin Biol Ther. 2010;10:301-7.

16. Demary W, Schwenke H, Rockwitz K, et al. Subcutaneously administered methotrexate for rheumatoid arthritis, by prefilled syringes versus prefilled pens: patient preference and comparison of the selfinjection experience. Patient Prefer Adherence. 2014;8:1061-71.

17. Thakur K, Biberger A, Handrich A, Rezk MF. Patient perceptions and preferences of two etanercept autoinjectors for rheumatoid arthritis: findings from a patient survey in Europe. Rheumatol Ther. 2016;3:245-56.

18. Thakur K, Biberger A, Handrich A, Rezk MF. Perceptions and preferences of two etanercept autoinjectors for rheumatoid arthritis: a new european union-approved etanercept Biosimilar (Benepali ${ }^{\circledR}$ versus etanercept (Enbrel®)-findings from a nurse survey in Europe. Rheumatol Ther. 2016;3:77-89.
19. Tischer B, Mehl A. Patients' and nurses' preferences for autoinjectors for rheumatoid arthritis: results of a European survey. Patient Prefer Adherence. 2018;12:1413-24.

20. Egeth M, Soosaar J, Nash P, et al. Patient and healthcare professionals preference for Brenzys vs. Enbrel autoinjector for rheumatoid arthritis: a randomized crossover simulated-use study. Adv Ther. 2017;34:1157-72.

21. Schwarzenbach F, Dao Trong M, Grange L, et al. Results of a human factors experiment of the usability and patient acceptance of a new autoinjector in patients with rheumatoid arthritis. Patient Prefer Adherence. 2014;8:199-209.

22. Kivitz A, Segurado OG. HUMIRA ${ }^{\circledR}$ pen: a novel autoinjection device for subcutaneous injection of the fully human monoclonal antibody adalimumab. Expert Rev Med Devices. 2007;4:109-16.

23. Zhao S, Chadwick L, Mysler E, Moots RJ. Review of biosimilar trials and data on adalimumab in rheumatoid arthritis. Curr Rheumatol Rep. 2018;20:57.

24. European Medicines Agency, Committee for Medicinal Products for Human Use (CHMP). Assessment report: Imraldi. International non-proprietary name: adalimumab. Procedure no. EMEA/ H/C/004279/0000. 2017. https://www.ema.europa. $\mathrm{eu} /$ documents/assessment-report/imraldi-epar-pub lic-assessment-report_en.pdf. Accessed 4 Oct 2018.

25. Biogen (Denmark) Manufacturing ApS. Imraldi solution for injection in pre-filled syringe [package insert]. Hillerød, Denmark: Biogen (Denmark) Manufacturing ApS; 2017. 